\title{
Stimulation of Phagocytosis and Production of Antibodies against Canine Herpesvirus Type 1 by Pidotimod (Adimod ${ }^{\mathrm{TM}}$ )
}

\author{
Edgar G. Valdivia Lara' ${ }^{1}$, Andrés Ángeles Aldana' ${ }^{1}$ Jesica I. Ángeles Solis², \\ Patricia Miranda Castro ${ }^{3}$, Juan C. Del Río García ${ }^{4}$, Guillermo Valdivia Anda ${ }^{{ }^{*}}$
}

\author{
${ }^{1}$ Laboratory of Microbial Pathogenicity, Multidisciplinary Research Unit, Faculty of Higher Education Cuautitlán, National \\ Autonomous University of Mexico, Cuautitlán Izcalli, Mexico \\ ${ }^{2}$ Laboratory DIVET ${ }^{\mathrm{TM}}$, Cuautitlan Izcalli, Mexico \\ ${ }^{3}$ Biotechnology Laboratory, UNAM, Cuautitlan Izcalli, Mexico \\ ${ }^{4}$ Laboratory of Mycotoxins, Multidisciplinary Research Unit, Faculty of Higher Education Cuautitlan, National Autonomous \\ University of Mexico, Cuautitlan Izcalli, Mexico \\ Email: guillermo897@hotmail.com, andresaa@lab-armstrong.com.mx, labdivet@prodigy.net,mx, mircas@unam.mx, \\ *valdivag@unam.mx
}

How to cite this paper: Lara, E.G.V., Aldana, A.Á., Solis, J.I.Á., Castro, P.M., García, J.C.D.R. and Anda, G.V. (2017) Stimulation of Phagocytosis and Production of Antibodies against Canine Herpesvirus Type 1 by Pidotimod (Adimod $\left.{ }^{\mathrm{Tm}}\right)$. Open Journal of Veterinary Medicine, 7, 38-47. https://doi.org/10.4236/ojvm.2017.74005

Received: March 23, 2017

Accepted: April 26, 2017

Published: April 29, 2017

Copyright $\odot 2017$ by authors and Scientific Research Publishing Inc. This work is licensed under the Creative Commons Attribution International License (CC BY 4.0).

http://creativecommons.org/licenses/by/4.0/

\section{(c) (i) Open Access}

\begin{abstract}
Neutrophils are the most important circulating phagocytes. Circulating monocytes and precursors of tissue macrophages also have the ability to phagocytize. Pidotimod (ADIMOD ${ }^{\mathrm{mm}}$ ) exerts immunostimulatory and immunoregulatory effects through the stimulation and regulation of cellular immune responses by lymphocytes Canine herpesvirus (CHV) mainly affect puppies between the first and second weeks of age, causing high morbidity in the litter. To date, there is only one commercial vaccine in Europe to prevent disease. In this work, inactivated CHV cultures were inoculated in rabbits, adsorbed and not adsorbed to chitosan nanoparticles. Phagocytosis in the presence or absence of specific antibodies was measured. Response of virus neutralizing antibodies was also evaluated. Adimod ${ }^{\mathrm{Tx}}$ enhanced the nonspecific and specific phagocytotic response. The association of the virus to the nanoparticles increased the phagocytic ability of blood cells; however, Adimod ${ }^{\mathrm{mm}}$ alone had a greater effect on phagocytic activity and generated a stronger immune response that corresponded to the increased phagocytosis $(\mathrm{p}<0.05)$. Moreover, the level of neutralizing antibodies was higher and increased more rapidly when Adimod $^{\text {Tw }}$ was used.
\end{abstract}

\section{Keywords}

Phagocytosis, Canine Herpesvirus, Pidotimod Stimulation 


\section{Introduction}

Antibodies are potent determinants of the humoral immune response. Although they are generated through interactions between $\mathrm{B}$ and $\mathrm{T}$ cells, antibodies trigger their cytotoxic effects by interacting with complement and innate effector cells; thus, they provide a functional link between the adaptive and innate immune systems [1].

Neutrophils are the most important circulating phagocytes as they provide the first line of defense against invading particles, especially bacteria [2]; however, circulating monocytes and precursors of tissue macrophages also have the ability to phagocytize [3].

Pidotimod [(R)-3-(S)-(5-oxo-2-pyrrolidinyl)-carbonyl-thiazolidine-4-carboxylic acid] [4] (ADIMOD ${ }^{\mathrm{m} x}$ ) exerts immunostimulatory and immunoregulatory effects on $\mathrm{T}$ lymphocytes, enhances and stimulates the immunological mechanisms involved in the humoral and cellular immunity mediated by $\mathrm{T}$ lymphocytes and simultaneously stimulates macrophage migration, which is an essential aspect of the cellular immune response that enables adequate phagocytosis and clearance of infectious microbes [4]. Pidotimod is almost completely absorbed when administered orally, and urine recovery reaches nearly $93 \%$ of the unchanged product. Furthermore, it is widely distributed throughout the body and mainly eliminated in the urine and feces, and its bioavailability reaches approximately $45 \%$ and is dose-dependent. Pidotimod undergoes only slight hepatic metabolism; therefore, it is excreted unchanged in the urine and no metabolites are known. Its plasma protein binding is very poor, which is advantageous to prevent interactions with other medications. Pidotimod has a half-life of approximately $4 \mathrm{~h}[5]$.

The mechanism of action of Pidotimod remains unknown but is considered to occur through the stimulation and regulation of cellular immune responses by lymphocytes, mainly $\mathrm{T}$ lymphocytes, with a concurrent stimulatory effect on macrophage migration. It should be noted that macrophages are involved in the cellular immune response; therefore, the display of Pidotimod is important for the mobilization of macrophages to allow them phagocytize and obtain the proper clearance of infectious microbes.

Pidotimod also presents a protective effect; although he did not have direct bactericidal or bacteriostatic activity, it globally stimulates the immune system, primarily macrophages.

To date, the role of Pidotimod in veterinary medicine, especially in small species, is unknown; therefore, the aim of this study was to evaluate its use as a vaccine adjuvant against Canine Herpesvirus (CHV).

\section{Methods}

Were used sixty rabbits of the New Zealand breed with an approximate weight of $1700 \mathrm{~g}$. The rabbits were obtained from the Animal Isolation Unit (Bioterio) of the Faculty of Higher Studies Cuautitlán, UNAM. Clinical and hematological evaluations were performed to ensure the health of the animals and set the initial parameters. Every procedure was conducted according to the use and care of 
experimental animals protocols mentioned in the Official Mexican Norm 062 (NOM062).

The virus was previously isolated from a 3-day-old dead puppy [6]; Canine Herpesvirus (CHV) was replicated in MDCK cells at a concentration of $10^{5}$ viral particles per $\mathrm{ml}$ and was inactivated by UV light exposure, as briefly described; the virus culture was placed in a $54 \mathrm{~mm}$ diameter glass Petri dish, capless at a distance of $20 \mathrm{~cm}$ from a mercury germicidal lamp (Osram HNS 10W), emitting mainly at $254 \mathrm{~nm}$ wavelength light. After $30 \mathrm{~min}$ an absorbed dose of approximately of $104 \mathrm{~J} / \mathrm{m}^{2}$ (3.6 quantum/nucleotide) occurred, this UV dose has been described to cause inactivation of alphaviruses and herpesvirus.

Chitosan nanoparticles (NANO) were prepared at the UNAM-FESC Biotechnology Laboratory, and the particles presented an approximate molecular size of $1000 \mu \mathrm{m}$ with a weight of approximately $1.5 \times 10^{6} \mathrm{Da}$ [7]. A 1:10 dilution of $10^{5} / \mathrm{ml}$ inactivated $\mathrm{CHV}$ was prepared using a chitosan solution. All preparations were photographed using transmission electron microscopy (TEM).

The experimental design was established as shown in Table 1.

All animals were bled from the jugular vein at $0,7,15,30,45$ and 60 days. A complete blood count, $\mathrm{CHV}$ antibody detection in the serum and an in vitro phagocytosis test were performed.

An in vitro test to evaluate specific and nonspecific phagocytic activity was modified from a previously described protocol [1]. Blood samples were collected in plastic syringes containing $30 \mathrm{U}$ of heparin per $\mathrm{ml}$ of blood. A $5 \%$ lysing solution was added to the sample, followed by centrifugation at $150 \mathrm{~g}$, at $6^{\circ} \mathrm{C}$, for 8 min to separate the leukocyte-rich plasma. The leukocytes were washed by adding Hank's balanced salt solution (HBSS) and centrifuging at $1118 \mathrm{~g}$ for $8 \mathrm{~min}$. The cell pellet was re-suspended in Medium $199\left(\right.$ In Vitro $\left.^{\text {Tm }}\right)$. The cell concentration was adjusted to $2.0 \times 10^{6}$ leukocytes per $\mathrm{ml}$.

The phagocytosis assay was performed as follows: a suspension of peripheral blood leukocytes at a concentration between $10^{3}$ and $10^{4}$ per ml was prepared, and $0.5 \mathrm{ml}$ of the suspension was added into 12 -well Nunc ${ }^{\text {tw }}$ plates. The chitosanvirus suspension $(0.5 \mathrm{ml})$ was added to six wells in each plate, and $0.5 \mathrm{ml}$ of the chitosan suspension was placed in the other six wells. Every well was filled with $0.5 \mathrm{ml}$ of MEM medium containing 5\% fetal bovine serum (In Vitro ${ }^{\mathrm{ms}}$ ) and 0.5

Table 1. Experimental design to determine the effect of Pidotimod (Adimod ${ }^{\mathrm{TM}}$ ) on phagocytosis in rabbits.

\begin{tabular}{|c|c|c|c|c|c|}
\hline Treatment & Group 1 & Group 2 & Group 3 & Group 4 & Group 5 \\
\hline CHVi $1 \mathrm{ml} \mathrm{sc}$ & Yes & & & & Yes \\
\hline $\mathrm{CHVi}+\mathrm{NANO} 1 \mathrm{ml} \mathrm{sc}$ & & yes & & & \\
\hline NANO $1 \mathrm{ml} \mathrm{sc}$ & & & Yes & & \\
\hline Adimod ${ }^{\bullet}$ oral seven days $2 \mathrm{ml}$ & & & & Yes & yes \\
\hline Inactivated MDCK cells $1 \mathrm{ml} \mathrm{sc}$ & & & Yes & Yes & \\
\hline
\end{tabular}

Twelve animals in each group $(n=60) \mathrm{CHVi}$, canine herpesvirus inactivated; NANO, chitosan nanoparticles; sc, subcutaneous. 
$\mathrm{ml}$ of serum from each rabbit. The plates were incubated overnight at $37^{\circ} \mathrm{C}$. The content of each well was transferred to an Eppendorf tube and centrifuged at $1118 \mathrm{~g}$ for $8 \mathrm{~min}$. at $6^{\circ} \mathrm{C}$, the pellet was washed three times with PBS, and the pellet was re-suspended in $0.5 \mathrm{ml}$ of MEM medium. For leukocyte counting, four smears from each well were fixed with cold acetone for $10 \mathrm{~min}$. Then, $15 \mu \mathrm{L}$ of fluorescein conjugated anti-CHV $\left(\mathrm{VMRD}^{\mathrm{m}}\right)$ were added. Finally, 100 cells were counted and the number of labeled cells per ml was calculated.

Total amount of serum antibodies against $\mathrm{CHV}$ was determined with a previously described seroneutralization test using $10^{3}$ virus particles per well [8] [9]. The sera were inactivated at $57^{\circ} \mathrm{C}$ for $30 \mathrm{~min}$, followed by a centrifugation step at $27,000 \mathrm{~g}$ for $10 \mathrm{~min}$ in a microcentrifuge. Because the virus used has a very low cytolytic effect, we employ a combination of routine test $\mathrm{SN}$ and observe cytopathic effect of the virus by the detection of cell infection by an immunoperoxidase technique, using antibodies against canine herpes virus of dog and anti canine IgG subsequently antibodies conjugated to peroxidase (Sigma ${ }^{\mathrm{TM}}$ ) developed by diaminobenzidine (Sigma ${ }^{\mathrm{rm}}$ ) on wells with cells [9]. Neutralizing antibodies were tested in all serum samples. A plaque formation test was used for viral titration: ten-fold dilutions of the virus culture (1:10, 1:100, 1:1000, 1:10,000) were made, and $0.5 \mathrm{ml}$ of each was added to each well of a 12 -well $\mathrm{NUNC}^{\mathrm{mix}}$ plate containing a monolayer of Madin-Darby canine kidney MDCK cells (In vitro $\left.{ }^{\mathrm{m}}, \mathrm{p} 117\right)$ at $90 \%$ confluence in minimal essential medium (MEM) (In vitro ${ }^{\text {mw }}$ ) with $5 \%$ newborn calf serum (NCS) (In vitro $\left.{ }^{\text {Tw }}\right)$. The cells were incubated for $1 \mathrm{~h}$ at $35^{\circ} \mathrm{C}$ to allow for viral absorption, with mixing every 15 min. Finally, MEM was added slowly with $1 \%$ newborn calf serum and $0.6 \%$ agarose (Bioline $e^{\mathrm{rm}}$ ) at $45^{\circ} \mathrm{C}$ to allow for solidification, and then incubated at $35^{\circ} \mathrm{C}$ for 3 days. A drop of formaldehyde $\left(J_{T B a k e r}{ }^{\mathrm{m}}\right)$ was then added to each well so that the agarose could be subsequently removed. The wells were washed carefully with phosphate buffered saline (PBS) and fixed with acetone/methanol $\left(\mathrm{ICR}^{\mathrm{im}}\right)$ for $10 \mathrm{~min}$. Subsequently, 0.5 $\mathrm{ml}$ of a 1:80 dilution of positive anti-CHV-1 control rabbit serum was added to each well and incubated for $30 \mathrm{~min}$ at $37^{\circ} \mathrm{C}$. The wells were washed three times with PBS, and anti-rabbit IgG peroxidase (Sigma Aldrich ${ }^{\mathrm{Tx}}$ ) was added and incubated for a further $30 \mathrm{~min}$ at $37^{\circ} \mathrm{C}$. The plate was washed three times with PBS, and a $0.01 \%$ diaminobenzidine solution (Sigma Aldrich ${ }^{\mathrm{Tw}}$ ) with hydrogen peroxide $\left(\mathrm{ICR}^{\mathrm{Tm}}\right)$ was added and held at $15 \mathrm{~min}$ at $37^{\circ} \mathrm{C}$ The plate was washed again with PBS and stained with Harris hematoxylin (Sigma Aldrich ${ }^{\mathrm{m}}$ ) for $15 \mathrm{~s}$, and the plates were examined microscopically for the presence of plaque forming units, termed peroxidase-positive spotlights (PPS), which were counted only in wells containing 20 - 100 plaques.

The neutralization assay was performed by incubating equal amounts of virus (50 PPS) with rabbit sera at different dilutions (1:4, 1:8, 1:16, 1:32, and 1:64; pretreated for $30 \mathrm{~min}$ at $\left.56^{\circ} \mathrm{C}\right)$ for $30 \mathrm{~min}$ at $37^{\circ} \mathrm{C}$. The mixture $(0.5 \mathrm{ml})$ was inoculated to $\mathrm{NUNC}^{\mathrm{m}}$ plates containing a monolayer of MDCK cells at $90 \%$ confluence. Viral adsorption was allowed for $1 \mathrm{~h}$ at $35^{\circ} \mathrm{C}$, while redistributing the inoculum every $15 \mathrm{~min}$, and MEM supplemented with $1 \%$ calf neonate serum and 
$0.6 \%$ agarose at $45^{\circ} \mathrm{C}$ was added slowly, allowing for solidification. The plate was incubated at $35^{\circ} \mathrm{C}$ for three days, and then a drop of $40 \%$ formaldehyde was added to each well and the agarose layer was removed the next day. The titer was calculated as the inverse of the highest dilution in which a reduction of at least $50 \%$ of the number of plaques was observed. A serum sample was considered negative if the $1: 8$ dilution of serum did not show a decrease of $50 \%$ or more in plaque formation.

The results were analysed by the Mann-Whitney U-test used Statistic ${ }^{\odot}$ software The numbers of samples are stated in the figure legends. The level of significance was set at $\mathrm{p}<0.05$. These is nonparametric test for the null hypothesis that there is no difference in phagocytosis between the two experiments. Assuming that we do not know if the experiments behave in a normal distribution, both experiments are independent and determine the difference between the two.

\section{Results and Discussion}

The average counts of blood leukocytes in the 12 animals were not significantly different ( $p>0.05$ ) over time (results not shown). Therefore, the doses used for the immunization of the rabbits were low because there were not showed inflammatory effects.

Abundant viral particles were adsorbed to the prepared chitosan particles, as observed on transmission electron microscopy (Figure 1).

In Figure 2, phagocytosis of viral particles in the absence (a) or presence (b) of specific antibodies was observed. Adimod $^{\mathrm{TM}}$ enhanced the nonspecific and specific phagocytotic response $(\mathrm{p}<0.05)$. In addition to their role in neutralization, antibodies mediate additional functions including the recruitment of innate

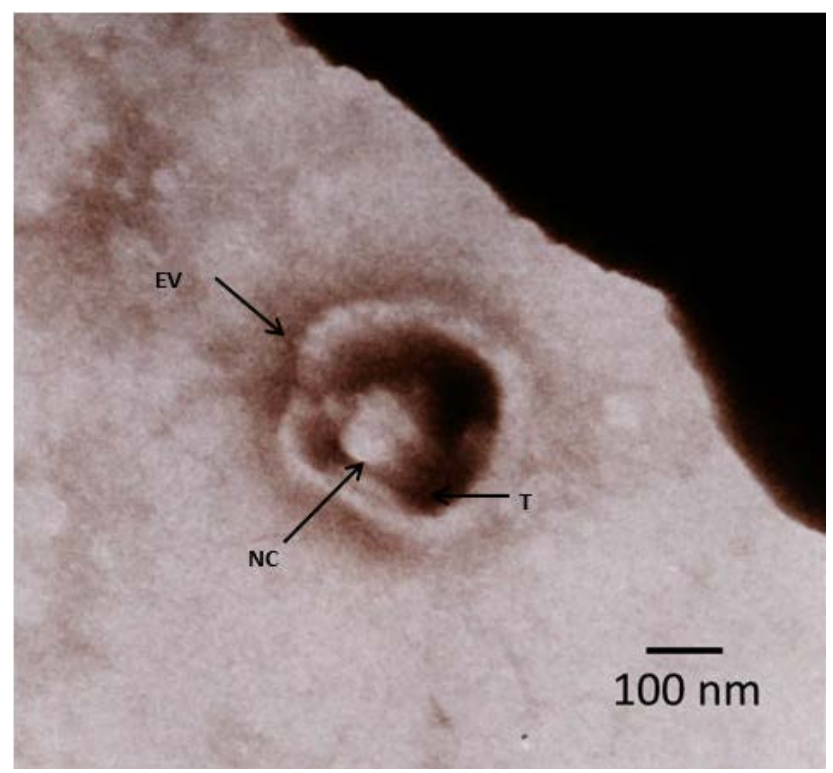

Figure 1. Micrograph taken by transmission electron microscopy showing adsorbed particles of herpesvirus (CHV) with an average diameter of $100 \mathrm{~nm}$ for the capsid and an average diameter of $240 \mathrm{~nm}$ for the sheath. Nucleocapsid (NC), the tegument (T) and the viral envelope (EV). Magnification: 20,000×. 


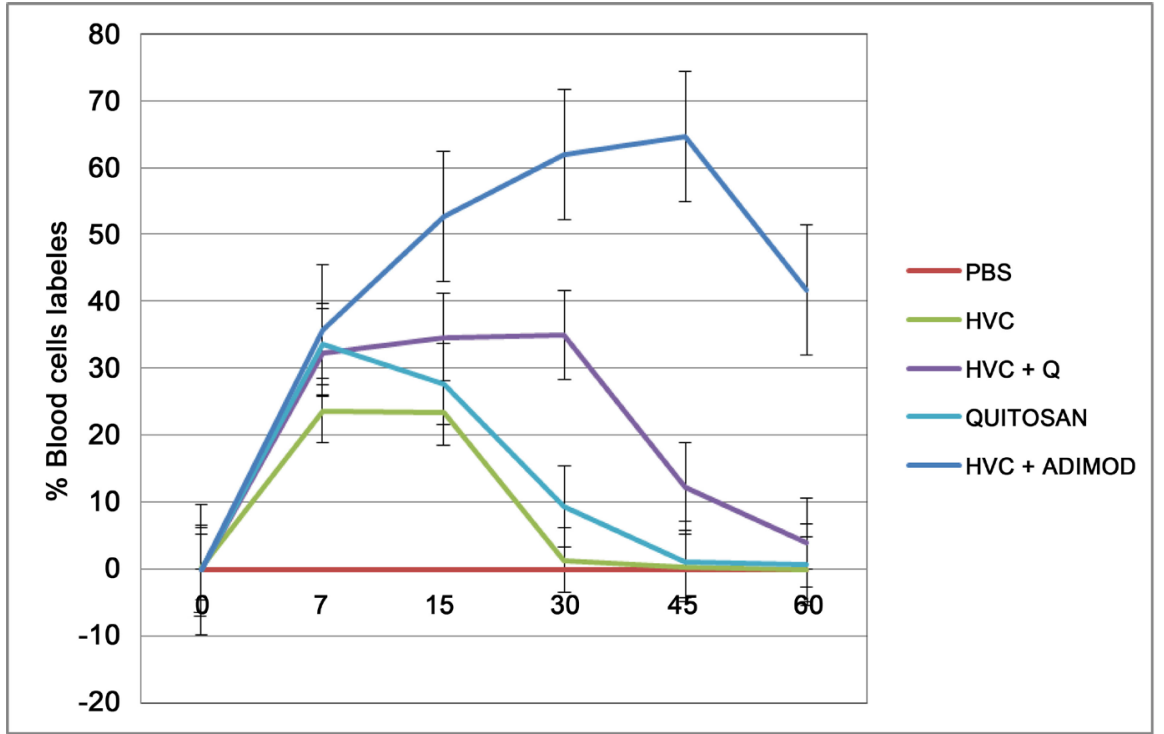

(a)

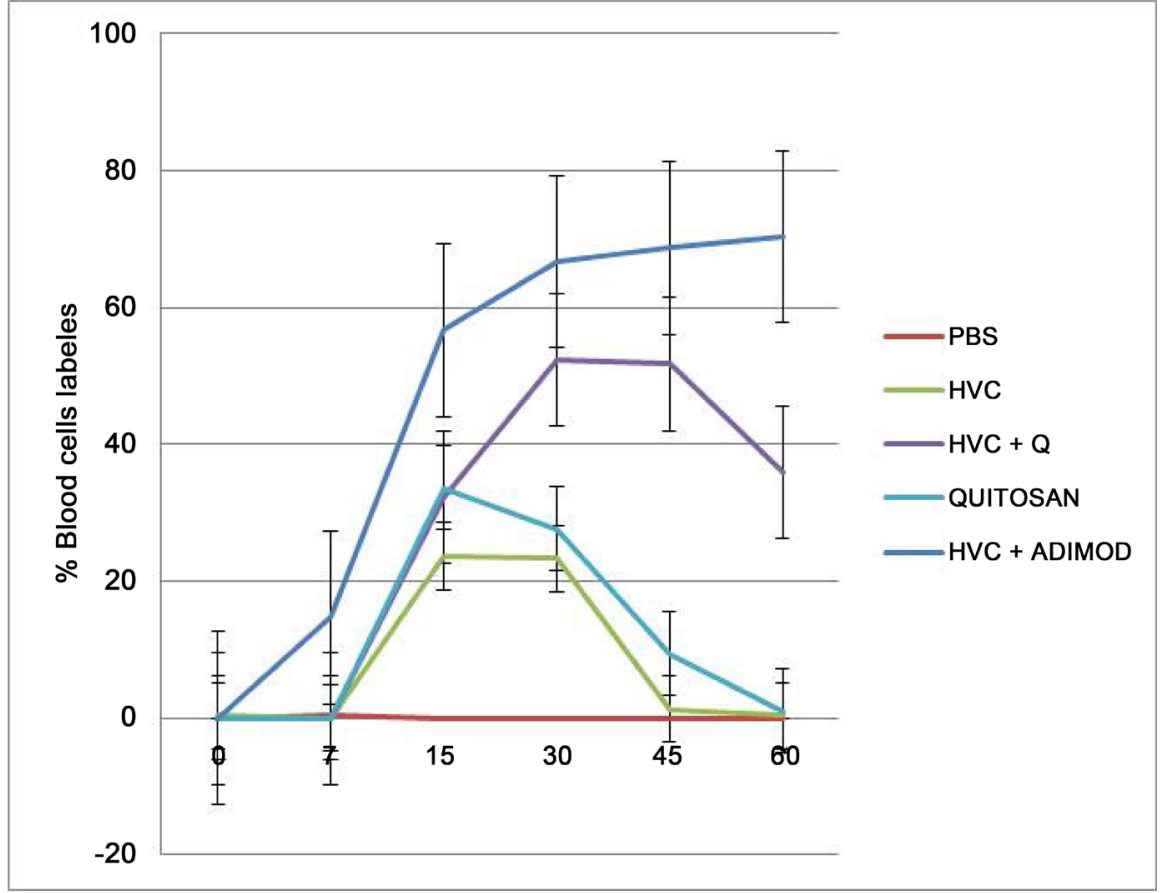

(b)

Figure 2. (a) Results indicate the average value for 12 rabbits per treatment. Chitosan particles adsorbed with inactivated canine herpesvirus (CHV) were placed in contact with ((a) blood leukocytes and evaluated by fluorescent antibodies against CHV. (b) the serum of rabbits and with leukocyte blood, and after incubation, they were evaluated using fluorescent antibodies against $\mathrm{CHV}$ ).

immune responses to eliminate antibody-opsonized material. Furthermore, antibodies promote phagocytosis, which may play an important role in the rapid containment and clearance of a pathogen following infection. However, robust assays that are able to capture differences in the quality of antibody-mediated phagocytosis are lacking [1]. Thus, in this study we developed a novel highthroughput assay by using monocytic cell blood to provide a platform to eva- 
luate antigen-specific antibody-mediated phagocytosis. Briefly, the antibodies of interest are captured on the surface of chitosan beads (NANO) coated with highly fluorescent spiked viral particles, and the beads are then incubated overnight with monocytes prior to analysis by immunofluorescence. Because the beads used may be coated with an antigen of choice, this assay allows the evaluation of antigen-specific phagocytosis without requiring purification of the respective antibodies.

We observed variation in the phagocytosis tests; however, comparison of data from microbiological in vitro studies on the phagocytosis and killing of $C$. albicans blastoconidia by phagocytes is hampered by divergent methodologies. The results of some studies are equivocal, and the reported differences may result from the various assay conditions and methods that have been used to determine phagocyte candidacidal activity [10]. However, to date, minor variations have been observed in other studies of the phagocytic ability of leukocytes.

We were not able to determine whether phagocytosis was performed by blood neutrophils or monocytes because both of these cell types have blood phagocytosis capability after opsonizing [11]; however, all rabbits in this study showed an average cell content of $73 \%$ neutrophils and $4.5 \%$ monocytes; therefore, most of the fluorescent cells observed corresponded to neutrophils.

In the present experiments, the association of the virus to the nanoparticles increased the phagocytic ability of blood cells; however, Adimod ${ }^{\mathrm{Tm}}$ alone had a high effect on phagocytic activity. Pidotimod was also observed to generate a stronger immune response that corresponded to the increased phagocytosis $(\mathrm{p}<$ $0.05)$.

In Figure 3, the results of seroneutralization tests are shown for each group, and the mean of the inverse of the highest dilution that provided $50 \%$ protection is plotted. Our results confirm that Adimod ${ }^{\text {tw }}$ enables a faster immune response $(\mathrm{p}<0.05)$ than chitosan's response after 45 days, which has been observed to be

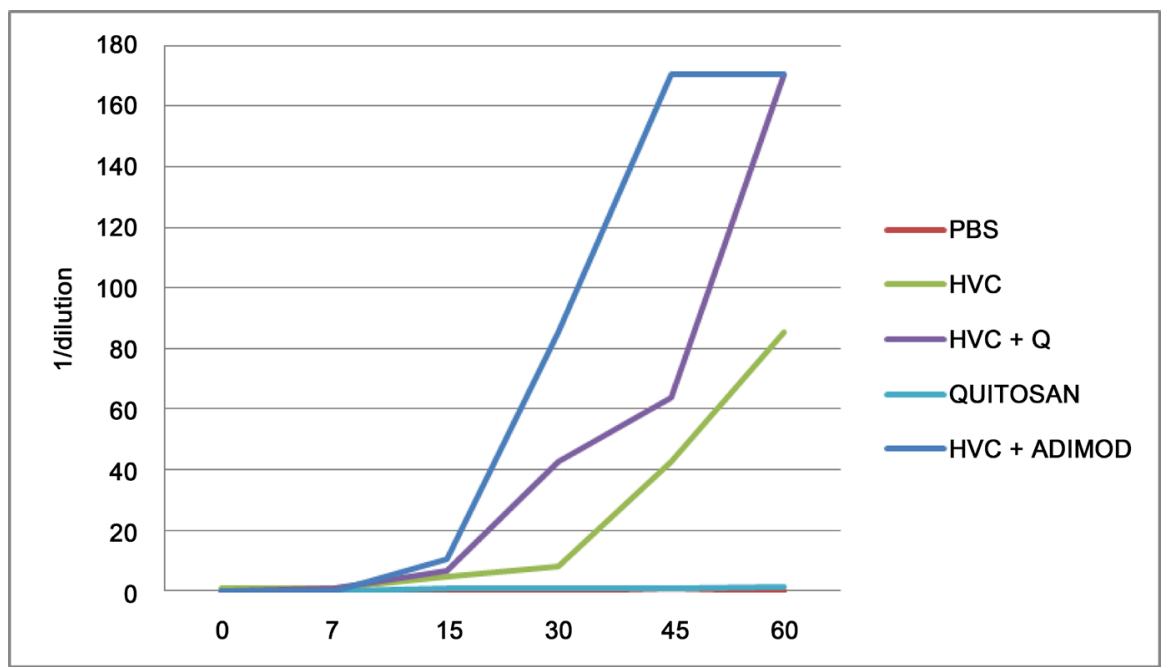

Figure 3. The results refer to 12 rabbits per treatment; the seroneutralization test was performed in triplicate using 103 viral particles per well, and the average of the inverse of the dilution that caused $50 \%$ lysis was plotted. 
as immunogenic as a vaccine adjuvant [12] [13].

Pidotimod [(R)-3-(S)-(5-oxo-2-pyrrolidinyl)-carbonyl-thiazolidine-4-carboxylic acid] has been shown to significantly increase the survival time after challenge with low doses of herpes simplex virus and influenza virus [4] Pidotimod was also shown to induce dendritic cell (DC) maturation and up-regulate MHC class II cell surface receptor (HLA-DR) and the co-stimulatory molecules CD83 and CD86, which are essential for communication with adaptive immune cells, and it was demonstrated that Pidotimod promotes strong and specific humoral and cellular immune responses in vivo when co-administered intranasally with an antigen model; it was also shown that administration by oral route increases resistance to viral infections [5] [14] [15] [16].

In this experimental design, we did not determine the combined effect of chitosan and Adimod ${ }^{\mathrm{rm}}$ because the purpose was to demonstrate Adimod's effect, but it is inferred that the immune response, using Adimod and nanoparticles combined, would possibly be higher and faster.

Studies developed to compare the intestinal absorption of various drugs in humans and experimental animals (e.g., rats and rabbits) have concluded that these animals are a good alternative model for preclinical studies for absorption in humans [17].

Vaccination of pregnant bitches has been effectively used in other countries to lessen the impacts of canine herpes virus infection in puppies; however, to date, no data is available for the use of vaccination against canine herpesvirus to protect an open population. Although it is true that protection against viral diseases is more efficient when mediated by cellular immunity, the development of higher amounts of serum antibodies in animals can help to eliminate viral reactivation after chronic infections or latency observed in herpes viruses; thereby decreasing the possibility of childbirth transmittance [18].

Evaluation of chemotaxis, phagocytosis and microbicidal killing may enable the differential diagnosis of immunodeficiency-related diseases as herpes virus infections observed in dogs and other species [11]. The methodology developed in our study may be useful to evaluate the effects of immunosuppressive diseases such as herpes virus and also to evaluate the effectiveness of immunomodulators and adjuvants.

The level of neutralizing antibodies was higher and increased more rapidly when Adimod $^{\mathrm{TM}}$ was used (Figure 2).

\section{Acknowledgements}

The work was partially funded by the project PAPIIT IT202114 "Evaluation of canine herpesvirus disease in Mexico and development of measures for its control and prevention.” of Universidad Nacional Autónoma de México, DGAPA.

\section{References}

[1] Ackerman, M.E., Moldt, B., Wyatt, R.T., Dugast, A.S., McAndrew, E., Tsoukas, S., Jost, S., Berger, C.T., Sciaranghella, G., Liu, Q., Darrell, J., Irvine, D.J., Burton, D.R. 
and Alter, G. (2011) A Robust, High-Throughput Assay to Determine the Phagocytic Activity of Clinical Antibody Samples. Journal of Immunological Methods, 366, 8-19. https://doi.org/10.1016/j.jim.2010.12.016

[2] Van Oss, C.J. (1986) Phagocytosis: An Overview. Methods in Enzymology, 132, 3 15. https://doi.org/10.1016/S0076-6879(86)32003-2

[3] Cline, M.J. and Lehrer, R.I. (1968) Phagocytosis by Human Monocytes. Blood, 32, 423-435.

[4] Masihi, K.N. (2000) Immunomodulatory Agents for Prophylaxis and Therapy of Infections. International Journal of Antimicrobial Agents, 14, 181-191. https://doi.org/10.1016/S0924-8579(99)00161-2

[5] Giagulli, C., Noerder, M., Avolio, M., Becker, P.D., Fiorentini, S., Guzmán, C.A. and Caruso, A. (2009) Pidotimod Promotes Functional Maturation of Dendritic Cells and Displays Adjuvant Properties at the Nasal Mucosa Level. International Immunopharmacology, 9, 1366-1373. https://doi.org/10.1016/j.intimp.2009.08.010

[6] Valdivia Lara, E.G., Barrón Romero, B.L., Cobos Marín, L., Ángeles Solis, J.I., González Gallardo, S., Cuenca Verde, C., Montaraz Crespo, J.A. and Valdivia Anda, G. (2016) Pathology Isolation and Identification of Canine Herpesvirus (CHV-1) in Mexico. Open Journal of Pathology, 6, Article ID: 67833.

[7] Miranda, C.S.P. and Lizárraga, P.E.G. (2012) Is Chitosan a New Panacea? Areas of Application. In: Karunaratne, D.N., Ed., The Complex World of Polysaccharides, InTech, Croatia, 3-46. https://doi.org/10.5772/51200

[8] Nothling, J.O., Hussy, D., Steckler, D. and Ackermann, M. (2008) Seroprevalence of Canine Herpesvirus in Breeding Kennels in the Gauteng Province of South Africa. Theriogenology, 69, 276-282. https://doi.org/10.1016/j.theriogenology.2007.09.022

[9] Valdivia, L.E.G., Angeles, S.J.I., Cuenca, V.C., Montaraz, C.J.A., Cobos, M.L., Del Río, G.J.C. and Valdivia, A.G. (2016) Canine Herpesvirus Seroprevalence and Associated Factors in Dogs of Mexico. Open Journal of Veterinary Medicine, 6, 149-162. https://doi.org/10.4236/ojvm.2016.610019

[10] Vonk, A.G., Wieland, C.W., Netea, M.G. and Kullberg, B.J. (2002) Phagocytosis and Intracellular Killing of Candida Albicans Blastoconidia by Neutrophils and Macrophages: A Comparison of Different Microbiological Test Systems. Journal of Microbiological Methods, 49, 55-62. https://doi.org/10.1016/S0167-7012(01)00348-7

[11] Chammas, P.P.C, Mitika, K. and Hagiwara, M.K. (1998) Evaluation of Neutrophilic Function (Chemotaxis, Phagocytosis and Microbicidal Activity) in Healthy Dogs and in Dogs Suffering from Recurrent Deep Pyoderma. Veterinary Immunology and Immunopathology, 64, 123-131.

https://doi.org/10.1016/S0165-2427(98)00130-5

[12] Surya, K., Mallapragada, S.K. and Narasimhan, B. (2008) Immunomodulatory Biomaterials Review. International Journal of Pharmaceutics, 364, 265-271. https://doi.org/10.1016/j.ijpharm.2008.06.030

[13] Gunbeyaza, M., Faraji, A., Ozkulb, A., Purall, N. and Senela, S. (2010) Chitosan Based Delivery Systems for Mucosal Immunization against Bovine Herpesvirus (BHV-1). European Journal of Pharmaceutical Sciences, 41, 531-545. https://doi.org/10.1016/j.ejps.2010.08.011

[14] Artali, R., Bombieri, G., Meneghetti, F., Nava, D., Ragg, E. and Stradi, R. (2003) Structural Characterization of a Dipeptide Compound with Immunostimulant Activity: 3-(5-Thioxo-L-prolyl)-L-thiazolidine-4-carboxylic Acid Il. Farmaco, 58, 883 889. https://doi.org/10.1016/S0014-827X(03)00146-0

[15] Li, C., Meng, Chen, D., Wang, Z., Han, H., Chen, H., Zhang, J. and Li, X. (2013) 
The Immunostimulatory Effect of Novel Immunostimulator CH2b with a Thiazolidin-4-One Ring on the Functions of LPS-Activated RAW 264.7 Macrophages In Vitro LPS. International Immunopharmacology, 17, 698-703.

https://doi.org/10.1016/j.intimp.2013.08.011

[16] Meng, M., Li, C., Chen, D., Wang, Z., Hong, Y., Chen, H., Li, X., Zhang, J. and Wang, F.S. (2013) Novel Synthetic Immunostimulators with a Thiazolidin-4-One Ring Promote the Cytotoxicity of Human NK Cells via ERK1/2 Activation In Vitro. International Immunopharmacology, 15, 655-660.

https://doi.org/10.1016/j.intimp.2013.02.019

[17] Zhao, Y.H., Abraham, M.H., Le, J., Hersey, A., Luscombe, C.N., Beck, G., Sherborne, B. and Coope, I. (2003) Evaluation of Rat Intestinal Absorption Data and Correlation with Human Intestinal Absorption. European Journal of Medicinal Chemistry, 38, 233-243. https://doi.org/10.1016/S0223-5234(03)00015-1

[18] Virgin, H.W., Wherry, E.J. and Ahmed, R. (2009) Redefining Chronic Viral Infection. Cell, 138, 30-50. https://doi.org/10.1016/j.cell.2009.06.036

Submit or recommend next manuscript to SCIRP and we will provide best service for you:

Accepting pre-submission inquiries through Email, Facebook, LinkedIn, Twitter, etc. A wide selection of journals (inclusive of 9 subjects, more than 200 journals)

Providing 24-hour high-quality service

User-friendly online submission system

Fair and swift peer-review system

Efficient typesetting and proofreading procedure

Display of the result of downloads and visits, as well as the number of cited articles Maximum dissemination of your research work

Submit your manuscript at: http://papersubmission.scirp.org/

Or contact ojvm@scirp.org 